DOI: https://doi.org/10.18485/philologia.2021.19.19.9

UDK: 821.111(73).09-31 Набоков В.

316.7(73)"1940/1950"

\title{
ODBLJESCI UTICAJA MASOVNIH MEDIJA KAO ELEMENTA POPULARNE KULTURE U LOLITI VLADIMIRA NABOKOVA
}

\author{
NATAŠA MIRKOVIĆ ${ }^{1}$ \\ Univerzitet Singidunum \\ Fakultet zdravstvenih i poslovnih studija \\ Valjevo, Srbija
}

Iako masovni mediji ne predstavljaju centralnu temu koju Vladimir Nabokov problematizuje u romanu Lolita, cilj ovog rada je da ispita njihovu ulogu u piščevom prikazu „prozaične" popularne i „vrednosno superiorne" visoke kulture kao i u prikazu konzumenata masovnih dobara. Kako bi se razumele osobenosti ere koju pisac ilustruje, u teorijskim razmatranjima masovni mediji su stavljeni u društveno-istorijski i naučni kontekst. Kvalitativnom analizom sadržaja, gde jedinicu analize predstavljaju odeljci romana koji sadrže informacije od značaja za ostvarivanje postavljenih ciljeva u radu, autor zaključuje da pisac uspeva da verodostojno oslika kulturnu scenu posleratnog perioda stavljajući u kontrast lik Lolite, kao predstavnika popularne kulture i lik Hamberta Hamberta, kao predstavnika visoke kulture. Takođe, u skladu sa stanovištem dominantnih kritičkih teorija masovnih medija, Nabokov dovodi u pitanje misaonu aktivnost publike koja se nađe pred sadržajima masovnih medija i ilustruje njihovu sugestivnu moć.

Ključne reči: masovni mediji, popularna kultura, Lolita, Hambert Hambert, kritičke teorije.

\section{UVOD}

Sa preko pola veka vremenske distance, sa sigurnošću možemo reći da roman Lolita danas zauzima značajno mesto u svetskoj književnosti, a kao kapitalno delo Vladimira Nabokova, često je podvrgnuta analizi i kritici. Iščitavajući delo, masovni mediji ne predstavljaju jednu od tema koja primarno pobuđuje istraživačku aktivnost i čitalačku radoznalost. Cilj ovog rada je da ponudi alternativnu perspektivu pri tumačenju dela,

1 Kontakt podaci (Email): mirkovic.natasa89@gmail.com 
odnosno da kroz prizmu masovnih medija prikaže piščevo viđenje potrošača masovne kulture posleratne ere i sagleda odnos popularne i visoke kulture.

Kako bi se ispunili ciljevi istraživanja, u početnim razmatranjima je objašnjen društveno-istorijski kontekst u kom se masovni mediji razvijaju, a koji korelira sa periodom u koji je smeštena radnja u romanu (četrdesete i pedesete prošlog veka). Takođe, objašnjene su i dominantne teorije o masovnim medijima koje datiraju iz prve polovine XX veka, odnosno kritička teorija Frankfurtske škole. Malo je verovatno da bi kritičke teorije pružile celovite i podrobne uvide pri proučavanju masovnih medija današnjice, ali isto kao i društveno-istorijskom kontekstu, značajna pažnja je posvećena naučnom kontekstu prve polovine XX veka jer autor rada nastoji da ispita kako se dominantni stavovi jedne ere reflektuju u Nabokovljevom prikazu masovnih medija i masovne kulture u opštem smislu.

U radu je korišćena kvalitativna analiza sadržaja, gde jedinicu analize predstavljaju odeljci romana koji sadrže informacije od značaja za predmet analize, a koji su u skladu sa ciljevima istraživanja i teorijskim okvirom i obuhvataju: piččev prikaz popularne i visoke kulture, predstavljanje konzumenata masovnih dobara u posleratnim okolnostima i odgovor publike (likova u delu) na poruke koje dobijaju posredstvom masovnih medija. U završnom delu rada su predstavljeni zaključci do kojih je autor ovog rada došao.

\section{DEFINICIJA I RAZVOJ MASOVNIH MEDIJA}

Masovni mediji predstavljaju sredstvo kojim se u procesu masovne komunikacije prenosi poruka, bilo da je reč o štampanim, digitalnim ili elektronskim medijima. Konkretnije, termin masovni mediji se odnosi na sredstvo komunikacije čiji je cilj da dopre do najšire publike (Lule 2013: 5). Medijska kultura obuhvata platforme kao što su radio, novine, časopisi, knjige, video igre, televizija i internet. Ona je komercijalna, a njeni proizvodi su dobra koja donose visok profit korporacijama čiji je cilj akumuliranje kapitala (Kellner 2003: 1).

Uporedo sa razvojem medija, javljaju se i pitanja o njihovom uticaju na pojedinca, institucije, društvo i kulturu. Ovakvo interesovanje rezultiralo je mnogobrojnim istraživanjima koja sežu još s početka XX veka, a tiču se formiranja stavova, uverenja, životnih navika kao i efektivnosti i efikasnosti masovne komunikacije (McQuail 1979: 73). Pregledom i analizom ovakvih istraživanja, Makvejl (1979: 91) navodi da mediji imaju moć da skrenu pažnju na određene probleme, rešenja i ljude; dodele status ili potvrde legitimitet; ubede i okupe mase; ponude mentalnu nagradu, odnosno razonode i zabave.

Kako je radnja u Nabokovljevom romanu Lolita smeštena u četrdesete i sam početak pedesetih godina, na samom početku je neophodno odrediti istorijski kontekst $u$ kom se masovni mediji razvijaju sredinom XX veka u Americi. Naime, posleratnu Ameriku karakteriše period prosperiteta i ekonomskog oporavka. Razvojni pravac koji zauzima može se ilustrovati na sledeći način: masovno zapošljavanje, masovna proizvodnja, masovno oglašavanje, masovna distribucija, masovno vlasništvo (Choen 2003: 105). Udaljavanjem od socijalističke ideologije istočnog bloka i učvršćivanjem kapitalizma 
dolazi do akumulacije javnog i privatnog kapitala. Ovakvom ekonomsko-političkom kolažu pogoduje povoj masovnih medija koji kroz pažljivo osmišljene sadržaje podstiču konzumerističke navike i utiču na kreiranje stila života kod prosečnog građanina.

Dvadeseti vek donosi svojevrsnu revoluciju u pogledu razvoja masovnih medija - pored ustaljenih štampanih formi, svet se po prvi put upoznaje sa elektronskim medjima poput radija, bioskopa i televizije. $U$ drugoj polovini četrdesetih godina radio je u domenu zabavnog programa američkoj publici nudio raznoliku šemu - emisija u trajanju od pet do petnaest minuta poput vesti i sapunica, zatim u trajanju od trideset do šezdeset minuta (drame, komedije, kvizovi) i višesatne blokove koji su se uglavnom sastojali od muzičkog programa. Tokom radne nedelje su se prikazivale sapunice i emisije mahom namenjene ženskom delu populacije, a u večernjim satima i vikendom su prikazivani sadržaji namenjeni i deci i odraslima (Foertsch 2008: 71). Najzastupljeniji muzički žanrovi su bili sving, bap, bluz, folk, r'n'b, gospel i kantri (Foertsch 2008: 82).

Uporedo sa razvojem filmske industrije, bioskop postaje široko dostupno mesto za razonodu i glavno uporište popularne kulture. Uprkos reorganizaciji studijskih sistema u drugoj polovini četrdesetih, 1946. godina beleži rekordnu posećenost bioskopima, a sve do poslednjih meseci dekade odlazak u bioskop je predstavljao vodeći vid zabave za većinu Amerikanaca (Foertsch 2008: 113). Za razliku od perioda stvaralaštva tokom Drugog svetskog rata kada su ratni sukobi preneti na platno, najzastupljeniji žanrovi ovog perioda su film noir i filmovi koji se bave društvenim pitanjima kao posledicom nacionalnog šoka (Foertsch 2008: 134).

Prevlast bioskopa, ali i opstanak drugih medija, dovedeni su u pitanje nakon Drugog svetskog rata kada su televizijski prenosi postali sve učestalija pojava širom sveta. Pre Drugog svetskog rata postojalo je samo 2000 televizora u Americi (Betts 2004: 56). Ovakav ograničen pristup i rani počeci razvoja televizije ubrzo su zaboravljeni s obzirom na to da je 1950. godina od ukupno 43,5 miliona američkih domaćinstava (Wang 2000: 38), 3,8 miliona posedovalo televizor (Betts 2004: 56).

Uprkos povoju elektronskih medija, pažnju treba posvetiti i štampanim medijima jer oni i dalje igraju značajnu ulogu u životu prosečnog Amerikanca. Ovakvu tvrdnju možemo ilustrovati na primeru populranih časopisa koji su upućeni gotovo svakoj ciljnoj grupi - liberalni dnevni list PM, afroamerički nedeljnik Pittsburgh Courier, Ladies' Home Journal namenjen ženama srednje klase, kao i širok dijapazon popularnih časopisa namenjenih beloj publici srednje klase kao što su Saturday Evening Post, Reader's Digest, Time i Life (Foertsch 2008: 46). Ovako bogata ponuda nudila je uvide u raspoloženje javnosti i čitalačke navike američkog društva u ovom periodu (Foertsch 2008: 46).

Na osnovu kratkog osvrta na medijski svemir posleratne Amerike, dolazimo do zaključka da su se medijski konzumenti našli u eri lakog pristupa informacijama i mogućnosti zadovoljavanja potreba za širokim spektrom polja interesovanja koji svaki pojedinac ili grupa mogu da imaju.

\section{KRITIČKE TEORIJE MASOVNIH MEDIJA}

Prve teorije, nazvane kritičkim teorijama, zauzimaju dominantnu ulogu u naučnom diskursu u prvoj polovini XX veka. One dolaze od klasično obrazovanih autora, koji su 
smatrali da će masovna proizvodnja popularnih sadržaja dovesti do razaranja sveta u kom su postojale vrednosti umetnosti i morala (Maširević 2020: 9).

Kada govorimo o kritičkim teorijama, nemoguće je ne spomenuti Frankfurtsku školu, čiji su predstavnici Adorno i Horkhajmer pružili jedan od najznačajnijih kritičkih osvrta na masovnu kulturu i čija se analiza kulturne industrije uzima kao polazna tačka u razmatranju popularne kulture kod mnogih teoretičara (Maširević 2020: 53). Kovanica „kulturna industrija” prvi put je upotrebljena kako bi skrenuli pažnju na industrijalizaciju i komercijalizaciju kulture pod okriljem kapitalizama (Kellner 1995: 29). Naime, kritička teorija Frankfurtske škole analizirala je masovnu kulturu u kontekstu industrijske proizvodnje ističući da su proizvodi kulturne industrije imali iste karakteristike kao i svaki drugi industrijski proizvod: komodifikaciju, standardizaciju i omasovljavanje. Međutim, kulturna industrija ima i svojevrsnu funkciju, odnosno treba da opravda postojanje kapitalističkog društva i integrisanje pojedinca u ovakvo društvo (Kellner 1995: 30).

Kritička teorija Frankfurtske škole dobija svoj potpun izraz kroz analizu kulturnih posledica koje prouzrokuju masovni mediji. Naime, pripadnici ove škole smatraju da su masovni mediji u potpunosti urušili svet tradicionalne visoke kulture, omasovili je i načinili dostupnom svima (Bennett 1982: 44). Visoka kultura devetnaestog veka, po mišljenju predstavnika ove škole, oduvek je bila antagonistička. Skrivena od sveta poslovanja i trgovine, negovala je ideale i težnje koje su bile duboko potisnute u svakodnevnici buržoaskog poretka (Bennett 1982: 44). Kao takva nudila je alternativu, odnosno drugu dimenziju u postojećim društvenim odnosima. Međutim, u eri kapitalizma umetnost gubi svoju antagonističku vrednost i postaje deo uspostavljenog poretka. Po njihovom mišljenju, mediji su napravili svet ozbiljne kulture lako dostupnim po cenu lišavanja kulture svog kritičkog aspekta.

Ideju o kulturi svog vremena, etape kroz koje je prolazila, kao i uticaj masovne proizvodnje i masovnih medija koji je pretrpela, Horkhajmer i Adorno u svom delu Dijalektika prosvetiteljstva objašnjavaju na sledeći način:

Kultura danas prožima sve svojom jednoličnošću. Filmovi, radio i časopisi formiraju sistem. Svaka grana kulture je jednoobrazna za sebe i sve su jednoobrazne u okviru sistema... Nekada je detalj bio element opozicije, bunio se protiv organizacije - u muzici je jedan harmoničan efekat mogao da nadvlada formu kao celinu, u slikarstvu je određeni detalj mogao da zaseni čitavu kompoziciju dela... Iako kulturna industrija daje prevlast detaljima i efektima, ona umanjuje njihovu neprilagođenost i podređuje ih formuli koja zamenjuje čitavo delo. Tako na primer, danas na filmu možemo još na samom početku lako predvideti ko će biti nagrađen, ko kažnjen, a ko zaboravljen. (Horkheimer/Adorno 2002: 99)

Zaokret u poimanju masovne kulture i masovnih medija kao njenog integralnog dela se javlja u drugoj polovini XX veka. Sve veći broj autora kritikuje kulturne hijerarhije i moralistički pristup proučavanju popularne kulture, ispoljavajući kritičko uvažavanje popularnog (Horowitz 2012: 5). U ovom periodu se razvijaju i studije kulture koje donose savremeniji pristup proučavanju popularnog, smatrajući ga jednako vrednim proučavanja kao iumetnost(Maširević2020: 10). Britanske studije kulture se razvijaju šezdesetih godina 
i predstavljaju značajniju školu koja nudi nove perspektive u razmatranju popularne kulture. Polazna tačka ovog pokreta temelji se na Gramšijevom modelu hegemonije², analizira prevlast vladajućih klasa, društvenih i kulturnih formi i pokušava da pronađe mehanizme za odupiranje dominantnim formama (Kellner 1995: 31).

Pozivajući se na studije društva, Frankfurtska škola pokušava da objasni odnos između ekonomije, države, društva, kulture i svakodnevnog života. Britanska škola za cilj ima isto, ali svoju analizu i tvrdnje temelje na studijama kulture. Ono što je fundamentalna razlika između ove dve škole jeste činjenica da Britanska škola, poput postmodernističkih teorija, anulira granicu između visoke i "niske" kulture, te stoga valorizuje forme kao što su film, televizija, popularna muzika (Kellner 1995: 32). Naime, ovaj pokret prepoznaje i priznaje razlike u sadržaju koje inkorporiraju visoka i masovna kultura, ali ne prihvata inferiorni položaj masovne (Zhen 2016: 27). U odbranu ovoj tvrdnji ističu da ako masovna kultura nastaje među ljudima, onda ti isti ljudi znaju kako da je konzumiraju aktivno, ali i selektivno. Štaviše, ljudi ne predstavljaju metu masovnih medija, nego su u interakciji sa njima i učestvuju u stvaranju masovne kulture (Zhen 2016: 27).

Pogrešno bi bilo zaključiti da postoji jasna granica koja određuje vremensku tačku do koje su sva stanovišta o masovnoj kulturi i medijima bila isključivo kritizerskog karaktera. Kako Horovic (2012: 8) navodi, krajem XIX i početkom XX veka pisci kao što je Vilijam Din Hauels, ali i naučnici poput Sajmona Patena uključuju elemente masovne kulture u svoj rad. Dvadesetih godina pisac i kulturni kritičar Gilbert Seldiz je o popularnoj kulturi pisao sa uvažavanjem. Isto tako, sredinom dvadesetih u krugovima kulturno angažovanih se razvija odgovor ka masovnim medijima koji nije bio prokapitalistički, ali ni antagonistički (Horowitz 2012: 8). Kritičke teorije su uzete kao primer koji ilustruje dominantnu klimu u naučnoj zajednici prve polovine XX veka jer je za dalju analizu bitno staviti masovne medije i u naučni kontekst.

\section{DISKUSIJA}

Bežeći od rata i političkih previranja koja su pogodila Evropu u prvoj polovini XX veka, život Vladimira Nabokova obeležila je kontinuirana migracija. Zajedno sa porodicom uspeva da napusti Pariz 1940. godine i otpočne novo životno poglavlje u Americi (Manolescu 2018: 102). U nastojanju da se pozicionira kao američki pisac, Nabokov počinje da piše na engleskom jeziku i da u dela iz perioda kreativnog rada na američkom tlu uključuje elemente eksploracije kontinenta u geografskom i kulturnom smislu. U romanu Lolita su ovakve piščeve namere oživljene kroz perspektivu Hamberta Hamberta, koji se s jedne strane divi prirodnim lepotama Amerike (Manolescu 2018: 105) i opisuje je kao „zemlju ružičaste dece i ogromnog drveća, gde će život biti toliko bolji nego u dosadnom, sivom Parizu" (Nabokov 2013: 34), dok se s druge strane na satiričan način odnosi prema masovnoj kulturi i konzumerističkom društvu od kojih je satkan Lolitin svet. Na ovaj način Hambert Hambert stvara dihotomiju između sebe kao

2 Hegemonija je definisana kao kulturološko i ideološko sredstvo pomoću kog dominantne grupe u društvu održavaju svoju poziciju tako što obezbeđuju „voljni pristanak" potčinjenih grupa. 
nosioca vrednosti visoke, evropske kulture i Lolite kao predstavnika nove generacije koji uživa u popularnim formama. Masovni mediji kao pudupirač masovne kulture su jedan od široko dostupnih izvora u delu na osnovu kojih se ovakve tvrdnje mogu graditi i dokazivati.

Kako bismo razjasnili kompleksan odnos popularnog i visokog, na samom početku neophodno je osvrnuti se na poreklo i uslove u kojima su glavni likovi odrastali. Hambert Hambert, narator u delu iz čije perspektive se vrši dalja analiza, rođen je u Parizu 1910. godine. Otac mu je bio švajcarskog, a majka engleskog porekla (Connolly 2009: 72). Rastao je „u blistavom svetu ilustrovanih knjiga, čistog peska, stabala narandži, dobroćudnih pasa, pogleda na more i nasmešenih lica" (Nabokov 2013: 15). U svom pomalo narcisoidnom maniru ističe „svi su me voleli, svi su me pazili, od perača sudova s keceljom, do gospode u flanelskim odelima" (Nabokov 2013: 15). Govoreći o svom životu, on navodi da je prvobitno planirao da diplomu stekne iz oblasti psihijatrije, ali da se kasnije ipak odlučio za englesku književnost.

Iako osećanja prema Loliti zauzimaju centralno mesto u delu, na samom početku Hambert se osvrće na prvo značajno seksualno iskustvo, ono koje je potencijalno i trasiralo njegove buduće afinitete. Anabel je bila sličnog društvenog staleža i mešovitog porekla kao i narator. Opisujući odnos između dva adolescenta Hambert piše „"mozgovi su nam bili u skladu sa mozgovima inteligentnih evropskih preadolescenata našeg vremena i okoline, i sumnjam da bi se ikakva individualna nadarenost mogla pripisati našem interesovanju za broj naseljenih svetova, beskonačnost, solipsizam i tome slično" (Nabokov 2013: 15). Već na uvodnim stranicama akcenat je stavljen na tradicionalno obrazovanje i akademske teme koje su pobuđivale njegovo interesovanje. Kao zreo čovek bavi se naučnim radom, a svoja istraživanja objavljuje u Analima psihofizike odraslih i Arktičkim istraživanjima (Nabokov 2013: 41), časopisima koji su proizvod Nabokovljeve fikcije. Odgovore na pitanja traži u enciklopedijama, upoznat je sa delima Dostojevskog, Flobera, Bodlera, prizori američkog tla ga podsećaju na pejzaže Kloda Lorena i El Greka (Nabokov 2013: 172). Nasuprot pozitivnom stavu prema visokim formama, Hambert Hambert o popularnim sadržajima govori s podrugljivim podtonom. Tako na primer opisujući svoj posao urednika reklama tvrdi da mu je odgovarala njegova „površnost i pseudoliterarni aspekt", te se time bavio kad nije imao pametnija posla (Nabokov 2013: 39). Dalje, u svom dnevniku piše (Nabokov 2013: 286): „Jednog dana izvadio sam iz kola gomilu tinejdžerskih časopisa i uništio ih. Znate već na šta sve to liči. U srcu kameno doba, a što se higijene tiče, nešto bliže, bar mikensko doba. Lepa, odavno prezrela glumica, ogromnih trepavica i sočnocrvene donje usne, preporučivala je šampon. Reklamoda." Kroz sarkastične aluzije na američke brendove i kroz svoje poglede na popularnu kulturu, Hambertovi komentari postavljaju jasnu granicu između „Visoke" i „niske" kulture, što dalje implicira da popularne kulturne forme u Americi nameću "niske" kulturne vrednosti široj publici. Isto tako, ne iznenađuje ga činjenica da Amerikanci voljno konzumiraju sve ono što se nudi na bilbordima i u reklamama (Floreani 2013: 34).

Sdruge strane, Lolita je rođena u Americi 1935. godine (Nabokov 2013: 39) i stasava u periodu koji karakteriše konsolidacija širokog spektra medija. Hambert Hambert je opisuje kao "krajnje nezgodno derište" ili "nepodnošljivo konvencionalnu devojčicu” koja uživa u "melodičnom vrelom džezu, popularnom plesu, lepljivom sladoledu sa 
čokoladnim prelivom, mjuziklima, filmskim časopisima" (Nabokov 2013:167). Narator nije "bio sasvim spreman za njene nastupe rastrojene dosade, za njeno naporno i naprasito gunđanje, njen izležavački, klonuli, tupooki stil, ni na ono što zove ludiranje" (Nabokov 2013: 167). Hambertovu procenu Lolite treba prihvatiti sa dozom skepse upravo zbog jednostrane perspektive koju čitalac dobija kroz njegove reči - on je optuženik koji teži da ubedi porotu, odnosno publiku u iskrenost $i$ bezazlenost svojih namera kroz odbranu izloženu u svojim memoarima. Lolita je opčinjena Holivudom, njeni uzori su starlete, čitalačko štivo se svodi na strip, njenu sobu krasi „reklama preko cele stranice, istrgnuta iz nekog luksuznog časopisa prikačena na zid iznad kreveta, između njuške nekog pevača i trepavica filmske glumice" (Nabokov 2013: 80). Po ugledu na svoje idole, i sama teži da jednog dana dobije „sporednu ulogu u sceni teniskog meča (ili) da možda čak dublira jednu od senzacionalnih starleta na reflektorima obasjanom teniskom terenu" (Nabokov 2013: 311). Hambert Hambert je bio zadužen za Lolitino obrazovanje. Uprkos svojim interesovanjima, i valorizaciji svega što možemo podvesti pod "visoku" kulturu, nikada nije uspeo da Lolitu "natera da pročita bilo kakvu knjigu osim takozvanih stripova, ili priča u američkim ženskim časopisima. Svaka iole ozbiljnija književnost asocirala ju je na školu i bila je sasvim sigurna da neće traćiti svoj raspust na takvo intelektualno štivo" (Nabokov 2013: 196).

Prikazom stavova o popularnoj kulturi kroz likove Hamberta Hamberta i Lolite, Nabokov dokazuje da je izuzetan poznavalac prilika u društvu sredinom XX veka. Rezultati istraživanja koje je Rejmond Forer sproveo 1955. godine pokazuju da tinejdžeri koji su slušali radio emisiju Mind Your Manners prihvataju savete koji su im predstavljeni, izuzev ukoliko se oni ne razlikuju od onih koje im daju roditelji, odnosno staratelji (Beniger/Herbst 1990: 224). Sobzirom na to da Lolita dolazi iz disfunkcionalne porodice (vrlo rano ostaje bez majke, a Hambert Hambert ne predstavlja adekvatnu očinsku figuru), ne čudi što joj Nabokov dodeljuje ulogu aktivnog konzumenta popularnih proizvoda koji svoj svet gradi na sadržajima popularnih časopisa, ugleda se na holivudske zvezde, a i sama želi da bude glumica. Pored toga, kako je Šarlota često zanemarivala Lolitine potrebe i kako sa dvanaest godina biva uvučena u incestuozne odnose, Lolita je primorana da neprimereno rano funkcioniše u svetu odraslih, te zadubljenost u stripove, časopise i filmove predstavlja vid eskapizma iz problematičnog okruženja. S druge strane, Nabokov Hambertu Hambertu vešto dodeljuje ulogu kritičara, pronicljivo uzimajući u obzir njegov nivo obrazovanja, staležne razlike, razliku u godinama i činjenicu da potiče iz konzervativnije Evrope. Takođe, piščevu opravdanu nameru da popularnu i visoku kulturu stavi u naporedni odnos, sagledavajući kontekst masovnih medija, potkrepljuje i činjenica da klima koja se formirala u društvu nije uvek pogodovala njihovom razvoju, a najvažnije teme koje su zabrinjavale javnost jesu da li mediji ugrožavaju moralna načela, demokratiju, kulturu, mentalno i fizičko zdravlje (Syvertsen 2017: 16).

Amerika nakon Drugog svetskog rata postaje vodeća industrijska sila u svetu. Ovaj period beleži i porast bruto nacionalnog proizvoda (Lune 2013: 13), što se reflektuje i krozakumuliranjenovcai kapitala kod pojedinaca. U ovakvim uslovima konzumeristička kultura dobija potpuni izražaj, a njena potpora postaju i široko dostupni masovni mediji koji kroz reklamne sadržaje teže da kreiraju potrebe pojedinaca. U praksi, ideja 0 posleratnom prosperitetu za prosečnog Amerikanca se ogleda u posedovanju potpuno 
opremljene kuće i automobila. U skladu sa ovakvom idejom, časopisi kao što je Better Homes and Gardens podsticali su čitaoce da kupuju obveznice i zasipali ih savetima i reklamama za uređenje doma (Choen 2003: 68). Nabokov vešto uspeva da prikaže trendove posleratne ere i dalekosežni uticaj medija na donošenje odlukai kreiranje stila života karakterizacijom Šarlote Hejz, koja bespogovorno primenjuje savete i instrukcije iz časopisa u svojoj svakodnevnici:

Menjalaje raspored nameštaja-iobradovalase kadje unekom traktatu o domaćinstvu otkrila da je „prihvatljivo raspariti dve komode koje idu uz divan i svetiljke koje idu uz njih". Zajedno sa spisateljicom knjige Vaš dom ste Vi , zamrzela je male slabašne stolice i tankonoge stočiće... Romane koje je čitala kad sam se doselio sada su zamenili ilustrovani katalozi i priručnici o uređenju doma. (Nabokov 2013: 90)

Sugestivnu prirodu masovnih medija pisac ilustruje i na primeru Lolite, koja poput svoje majke, usvaja poruke koje joj se nude posredstvom medija:

Ona je verovala, s nekom vrstom nebeske vere, u svaku reklamu ili savet koji bi se pojavili u Filmskoj ljubavi ili Svetu filma - „Starasil satire akne”, ili „Vi, cure, što nosite košulje preko farmerki, bolje pripazite šta radite, jer Džil kaže da se to ne radi". Ako je na velikim panoima kraj puta pisalo: „Kupite poklone kod nas" - morali smo tamo da svratimo... Ako je reklama nekog kafea pozivala na "Ledena pića", ona je automatski reagovala na to, iako su pića svuda bila ledena. Ona je bila ta kojoj su se obraćale reklame - idealan potrošač, subjekat i objekat svakog obmanjivačkog plakata. (Nabokov 2013: 167)

Na osnovu prethodnih navoda iz romana zaključujemo da pisac Šarlotu i Lolitu oslikava kao pasivnu publiku koja ne razmatra implikacije predstavljenih sadržaja. Ovakav Nabokovljev opis se podudara sa stanovištem Frankfurtske škole. Adorno i Horkhajmer takođe smatraju da je publika pasivna i da se njom lako manipuliše. Potrošači masovne kulture nisu subjekti, već samo objekti jer se kulturna industrija svodi na proizvodnju dobara namenjenih masama (Maširević 2020: 54). Konzumiranje ovakvih proizvoda vodi u površnost u svim oblastima ljudske komunikacije (Maširević 2020: 54), te Lolita postaje „nepodnošljivo konvencionalna devojčica”, a Šarlota „jedna od onih žena čije uglađene reči odgovaraju klubu ljubitelja knjige, ili klubu ljubitelja bridža, ili ma kojoj smrtonosnoj konvencionalnosti" (Nabokov 2013: 45).

Nabokov prepoznaje bioskop i film kao neizostavne činioce koji upotpunjuju ideju o masovnoj kulturi i društvu, te nastoji da umešno uključi opšte trendove u roman kako bi pružio celovitu sliku ali i kontekst za razumevanje Lolitinog sveta. I sam Nabokov je tvrdio kako ne razmišlja ni na jednom jeziku, već u slikama (Bozovic 2018: 174), te ne iznenađuje izuzetan kinematografski potencijal njegovih dela. Piščevo interesovanje za film se javlja jako rano i ne jenjava tokom čitavog života - okušao se kao glumac, pisao scenarije i pregovarao o filmskoj adaptaciji svojih dela (Bozovic 2018: 179). Kako je pisac živeo u periodu od 1899. do 1977. godine, možemo zaključiti da je posvedočio svim fazama razvoja ovog medija. Nabokovljeva opčinjenost filmom u velikoj meri počiva na komercijalnoj kulturi i potrošačkom društvu. Prednost je davao nemom filmu 
u odnosu na zvučni, a cenio je filmove koji samosvesno koriste osobenosti ovog medija (Bozovic 2018: 179). Kao filmski kritičar Nabokov je u najširem smislu bio marksista koji je u svojim delima, između ostalog i u Loliti, odavao prizvuk Adornove i Horkhajmerove kritike kulturne industrije (Bozovic 2018: 179).

Horkhajmer i Adorno vide film kao medij koji najpre zabranjuje gledaocu misaonu aktivnost. Iako film traži brzinu i sposobnost zapažanja za adekvatno shvatanje poruka, kod gledaoca se upravo ove sposobnosti suspenduju, ukoliko ne želi da mu umakne neka od činjenica koje jure mimo njega (Maširević 2020: 54). Hambert Hambert poseduje izvesno radno iskustvo u oblasti marketinga s obzirom na to da se njegov prvi posao u Americi sastojao u uređivanju reklama za parfeme, te ne iznenađuje njegovo razumevanje mehanizama na kojima masovni mediji počivaju, u konkretnom slučaju film i bioskop. Stoga, motiv iza Hambertovog pristanka da učestvuje u maničnoj poseti bioskopima skriven je u nameri da uljuljka Lolitu kako bi ostvario svoje seksualne pretenzije prema njoj:

U to vreme Lo je još uvek strasno volela da ide u bioskop. Odgledali smo, požudno i neprobirljivo, o, ne znam, sto pedeset ili dvesta filmova tokom te godine, a u nekim periodima učestalijeg odlaženja u bioskop gledali smo mnoge filmske žurnale i po pet-šest puta, jer se tokom iste nedelje jedan isti žurnal prikazivao uz različite filmove i proganjao nas iz grada u grad. Njeni najomiljeniji žanrovi bili su ovim redom: mjuzikli, gangsterski filmovi, vesterni. (Nabokov 2013: 192)

Kao što je navedeno u uvodnim razmatranjima, 1946. godina beleži rekordnu posećenost bioskopima, a sve do poslednjih meseci dekade odlazak u bioskop je predstavljao vodeći vid zabave za većinu Amerikanaca (Foertsch 2008: 113). Ako ovakve podatke uzmemo u razmatranje i ako za trenutak film lišimo manipulativne uloge koju mu Nabokov pripisuje, primarno, na površinskom nivou, pisac kroz niz scena utkanih u čitavo delo ilustruje navike posleratnog društva. Tako na samom početku kroz Šarlotino detaljno prepričavanje sadržaja filma koji prati živote boksera i sveštenika saznajemo da je uživanje u ovoj grani umetnosti porodična praksa u domu Hejzovih. Zatim, tokom perioda provedenom na putu kroz Ameriku saznajemo da su Hambert Hambert i Lolita u gradiću Lepingvilu odgledali sve filmove koji se prikazuju. Doživljaj Amerike osnažuje i Hambertov opis Brajslenda "gde se dugačak red ljudi, uglavnom dece i staraca, već formirao pred blagajnom bioskopa" (Nabokov 2013: 131).

Radio je četrdesetih godina publici nudio bogat program i uključivao je desetine emisija koje su bile namenjene najrazličitijim ciljnim grupama. Samo neki od žanrova su komedije, sapunice, vesterni, trileri, kriminalističke emisije, kvizovi, informativni program itd. Najpopularnije sapunice emitovane u dnevnim terminima su Ma Perkins, koja prati život plemenite udovice i njene dece, Romansa Helene Trent koja govori o tridesetpetogodišnjoj neudatoj ženi i izgledima da stupi u brak (Foertsch 2008: 79). Kada je reč o emisijama za decu, izdvajali su se Usamljeni rendžer, Tom Miks, Zeleni stř̌ljen i Supermen (Foertsch 2008: 80). Neizostavni deo radijske šeme su bili muzički blokovi, a najzastupljeniji žanrovi su bili sving, bap, bluz, folk, r'n'b, gospel, kantri. Pored radija, rastuća industrija ploča, notnih zapisa i džuboksa omogućila je veću vidljivost lokalnim bendovima i manje poznatim autorima (Foertsch 2008: 82). 
Radio kao i dalje uticajan medij igra značajnu ulogu u romanu Lolita i njegova uloga je dvojaka: (1) da učvrsti piščev prikaz kulturnog miljea u Americi; (2) da suprotstavi popularne i "visoke" vrednosti. U prvom delu romana, upoznajući se sa životom predstavnika srednje klase u Americi, odnosno Lolitom i Šarlotom, čitalac saznaje da je radio sveprisutan u domu Hejzovih. Hambert Hambert se vrlo brzo prilagođava i uči o novom okruženju, te na osnovu toga da li je radio uključen ili isključen zaključuje da li je Lolita u kući (Nabokov 2013: 59): „Nalik na zrak, klizim u mislima u salon, gde zatičem nemi radio... Moja nimfica znači uopšte nije u kući! Nestala!" Radio je čest saputnik protagonista na putu širom američkog kontinenta, te ga možemo čuti u predvorju hotela, na benzinskim pumpama, areni za rolšuanje. Za Lolitu kao konzumenta popularnih formi radio predstavlja jednako zadovoljstvo kao i strip, časopisi za tinejdžere ili film. On ispunjava njenu svakodnevncu i svodi se na nivo obaveznog, podrazumevajućeg (Nabokov 2013: 199): „Naslepo je uključila radio koji je instinktivno pronašla, i odmah legla na divan u dnevnoj sobi, sa hrpom starih časopisa do kojih je došla na isti, precizan, slep način." S druge strane, sadržaje koje dobija posredstvom radija, kao i uostalom sve druge popularne sadržaje, Hambert Hambert doživljava kao površne, umetnički ništavne i ismejava njihovu pitkost i sentimentalnost:

Samo Gospod zna koliko sam novčića nahranio blistave muzičke automate koji su svirali uz svaki naš obrok! I sad čujem nazalne glasove nevidljivih ljudi koji su joj pevali serenade, osoba sa imenom Semi, Džo, Edi, Toni, Pegi, Gaj, Peti, Reks i njihove popularne sentimentalne pesmice koje su mom uhu bile međusobno slične koliko i sve vrste njihovih bombona mom nepcu. (Nabokov 2013: 167)

Međutim, uprkos težnji da popularne forme izvrgne ruglu i da pokaže njihov vrednosno inferioran položaj u odnosu na evropsku kulturu čiji je predstavnik, Hambert ne uspeva da se u potpunosti odupre procesu amerikanizacije. Kroz konzumerističke navike, učestalo odlaženje u bioskop, pevušenje popularnih pesmica, Hambert od oštrog kritičara postaje aktivan učesnik u konzumiranju popularnog. Značajno je istaći da ovakva aktivnost ne podrazumeva da on u celosti prihvata i izjednačva popularne sadržaje sa visokim, već da ih razume, odnosno da razume njihovu univerzalnost, dopadljivost i potencijal da uključe širku publiku. Upravo kroz graničnu tačku Hambertovog razumevanja i (ne)prihvatanja pisac reflektuje sposobnost medija da zabave, pošalju poruke i utiču na izbore. U Hambertovom slučaju, on ih koristi kao instrument da se približi Loliti, da pokaže kako je dostojan njene posvećenosti i kako je zapravo on adekvatan partner.

\section{ZAKLJUČAK}

Sa konsolidacijom širokog spektra masovnih medija poput televizije, bioskopa, radija, časopisa, stripa i knjige, društvene i kulturne strukture u Americi nakon Drugog svetskog rata se suočavaju sa korenitim promenama. Uvidima u istorijski kontekst razvoja masovnih medija, dolazi se do zaključka da Vladimir Nabokovu svom kapitalnom delu Lolita precizno i verodostojno uspeva da opiše medijsku paletu pred kojom su se 
konzumenti masovne kulture našli. Takođe, pisac kroz odnos koji likovi u delu grade prema masovnim medijima problematizuje poziciju koju zauzimaju popularna i visoka kultura. Pokušavajući da ilustruje ovaj kompleksan odnos, autor Hambertu Hambertu dodeljuje ulogu nosioca onoga što se u eri modernizma smatralo „visokim" vrednostima i kroz Hambertove maštovite i ironične komentare dovodi u pitanje stavove i obrasce ponašanje koji su nastali kao posledica omasovljavanja kulturnih dobara, a čiji su podupirač bili i sami masovni mediji. Karakterizacijom Lolite kao nosioca „popularnih" vrednosti, Nabokov se, između ostalog, rukovodi kriterijumima poput starosne razlike, nivoa obrazovanja, socioekonomskog porekla i načina odrastanja, što implicira da pisac razume profil tipičnog potrošača masovne kulture.

Dovodeći roman u vezu sa dominantnim kritičkim teorijama masovnih medija u prvoj polovini XX veka, dolazi se do zaključka da je publika koja se nađe pred sadržajima plasiranim posredstvom masovnih medija pasivna, što Nabokov ilustruje na primeru Lolite i Šarlote Hejz, koje bez preispitivanja prihvataju poruke koje su im upućene i na osnovu kojih organizuju svoju svakodnevnicu, donose odluke, formiraju stavove i aspiracije. Na posletku, upravo kroz bezrezervno usvajanje predstavljenih sadržaja, kao i kroz Hambertovo stavljanje medija u službu manipulativnog sredstva sa krajnjim ciljem da se približi Loliti, Nabokov ilustuje sugestivnu moć masovnih medija.

Iako masovni mediji nisu centralna tema u romanu Lolita, neosporan je njihov potencijal da rasvetle višestruke fenomene u delu i ponude alternativni okvir za buduće analize i tumačenja.

\section{LITERATURA}

Beniger, J. and S. Herbst. 1990. Mass Media and Public Opinion: Emergence of an Institution. In M. T. Hallinan (ed.) Change in Societal Institution. New York: Plenum Press, 211-231.

Bennett, T. 1982. Theories of the Media, Theories of Society. In M. Gurevitch (ed.) Culture, Society and the Media. London: Methuen, 30-55.

Betts, R. 2004. A History of Popular Culture. New York: Routledge.

Bozovic, M. 2018. Nabokov's Visual Imagination. In D. Bethea and S. Frank (ed.) Vladimir Nabokov in Context. Cambridge: CUP, 174-181.

Chandler, D. 1995. Marxist Media theory. [Internet]. Dostupno na: http://visualmemory. co.uk/daniel/Documents/marxism/marxism.html [20.9.2017].

Choen, L. 2003. A consumers' Republic: The politics of mass consumption in postwar America. New York: Vintage.

Connolly, J. W. 2009. A Reader's Guide to Nabokov's 'Lolita'. Boston: Academic Studies Press.

Floreani, T. 2013. Fifties Ethnicities: The Ethnic Novel and Mass Culture at Midcentury. Albany: State University of New York Press.

Foertsch, J. 2008. American Culture in the 1940s. Edinburgh: Edinburgh University Press. Horkheimer, M. and T. Adorno. 2002. Dialectic of Enlightenment. Stanford: Stanford University Press.

Horowitz, D. 2012. Consuming pleasures: Intellectuals and popular culture in the postwar world. Philadelphia: University of Pennsylvania Press. 
Kellner, D. 1995. Media Culture. New York: Routledge.

Kellner, D. 2003. Media Spectacle. New York: Routledge.

Lule, J. 2013. Understanding Media and Culture: An Introduction to Mass Communication. Washington D.C.: Saylor Foundation.

Manolescu, M. 2018. East to West Coast. In D. Bethea and S. Frank (eds.) Vladimir Nabokov in Context. Cambridge: CUP, 102-110.

Maširević, Lj. 2020. Popularna kultura. Beograd: Beogradska politehnika.

McQuail, D. 1979. The Influence and Effects of Mass Media. In J. Curran (ed.) Mass Communication and Society. New York: Sage Publication, 70-93.

Nabokov, V. 2013. Lolita (prev. F. Rigonat). Beograd: Lom.

Syvertsen, T. 2017. Media Resistance: Protest, Dislike, Abstention. Basingstoke: Springer Nature.

Wang, C. 2000. Projections of the Number of Households and Families in the United States: 1999-2025. In D. E. Gerald (ed.) Federal Forecaster Conference, 2000: Papers and Proceedings. Washington, D.C.: U.S. Dept. of Education, Office of Educational Research and Improvement, 33-43.

Zhen, L. 2016. Relationship Between Mass Media and Mass Culture: Frankfurt School and Cultural Studies School. Canadian Social Science 12 (1), 23-28.

\section{SUMMARY}

\section{REFLECTIONS OF MASS MEDIA AS AN ELEMENT OF POPULAR CULTURE IN VLADIMIR NABOKOV'S LOLITA}

The aim of this paper is to highlight how Vladimir Nabokov employs mass media in his illustration of "prosaic" popular, and "superior" high culture, and in his portrayal of mass consumer society in his novel Lolita. In order to identify principal aspects of the era the writer strives to mirror, the mass media are set in the context of dominant mass media theories and socio-historical shifts. The author of this paper uses qualitative content analysis, where the unit of analysis comprises novel passages that provide relevant information to achieving the aims of this research. The author concludes that Nabokov credibly portrays the cultural scene of the post-war period by contrasting the characters of Lolita, a representative of popular culture, and Humbert Humbert, a representative of high culture. Finally, Nabokov challenges the ability to critically interpret media content presented to the audiences, which is in line with the issues critical theories of mass media attempt to address.

KEYWORDS: mass media, popular culture, Lolita, Humbert Humbert, critical theories.

PODACI 0 ČLANKU: Originalni naučni rad

Primljen: 5. marta 2021. Ispravljen: 5. septembra 2021. Prihvaćen: 18. septembra 2021. 